\title{
EVALUATION OF HEALTH-CARE WASTE TREATMENT TECHNOLOGIES BASED ON ANALYTIC NETWORK PROCESS
}

\author{
Xi Chen ${ }^{1} \cdot$ Yaya Sun ${ }^{2}$ \\ $\mathrm{Xi}$ Chen \\ xchen@xidian.edu.cn \\ Yaya Sun \\ yysun@stu.xidian.edu.cn \\ 12 School of Economics \& Management, Xidian University, Xi'an 710071, China
}

\begin{abstract}
The safety of health-care waste(HCW) treatment is an important part of maintaining the health of the group, and it is very crucial to choose an appropriate method of HCW management. Based on the understanding of the HCW disposal methods and the consideration of the interdependence of indicators, the objective of this paper is to give a reasonable evaluation of the $\mathrm{HCW}$ treatment alternatives by using Analytic Network Process (ANP). Finally, steam sterilization is the best method of HCW management at this stage, so as to further maintain the health of the community and improve living standards of the people.
\end{abstract}

Key words: HCW, ANP, evaluation index

\section{Introduction}

With the rapid development of science and technology, the medical and health services have also steadily grown in recent decades. But medical and healthcare wastes have sharply increased. In Poland, there are approximately 40,000 waste generators and each year they produce on average 45,000 tons of medical waste, of which more than $90 \%$ is classified as infectious. In the case of medical waste as a whole, hazardous wastes represent $10-25 \%$ of the total HCWs. Hazardous HCWs include, but are not limited to, infectious, chemical and radioactive wastes and may pose various environmental and health risks (Ata $\mathrm{R}$ et al. 2016).

Inappropriate $\mathrm{HCW}$ management can cause environmental pollution. Besides, it can also give rise to rapid growth of insects, rodents and worms and lead to the spread of diseases caused by contaminated blood such as cholera, hepatitis and typhoid, in which people's lives are threatened. Correct disposal HCW can not only reduce and avoid the waste of resources, and improve the irrational medical system, but also further protect society and environment and ensure the safety of citizens. Therefore, the proper and reasonable disposal HCW plays a vital role in medical and environmental management. At the same time, many scholars have conducted researches on $\mathrm{HCW}$.

The researches on the HCW treatment technologies are mainly divided into two categories. One is to investigate the current situation of the medical treatment through surveys or personnel interviews. Patwary et al. (2011) investigated the impacts of the environmental safety and potential risks, especially individuals who are currently working on $\mathrm{HCW}$ in Dhaka. Manga et al. (2011) carried out a waste management system based on five surveys about health care facilities in southwestern Cameroon Assessments to identify current 
practices and areas for improvement; Ferreira and Teixeira (2010) analyzed the HCW management practices in hospitals of the Algarve Region, Portugal, and assessed the risk perception of the healthcare staff and the risks to staff groups posed by waste management in these hospitals. Abd El-Salam (2010) investigated HCW management in 8 Pride Hospitals in Egypt, to determine the overall wastes productivity and physicochemical characteristics.

The other category is based on the status quo, gives some solutions and gains the best disposal technology. Liu et al. (2013) used VIKOR fuzzy multi-criteria decision-making to study HCW disposal methods; Liu et al. (2015) considered the subjective and objective importance coefficient criteria of evaluation by MULTIMOORA method of the interval 2tuple language variable (called ITL-MULTIMOORA) to select alternatives; Ata et al. (2016) used SAT methodology to qualitatively and quantitatively evaluate infectious wastes; Chao et al. (2016) presented a hybrid 2-tuple-induced TOPSIS decision method. The combination of 2-tuple induced distance operator and optimization technique was used to solve the problem.

Although academics on HCW disposal have made some achievements, they also have contributed to the research on methodologic assessment. However, the previous researches still have shortcomings and problems that need to be improved. The above methods are not only indicators considered incompletely, but the correlation between indicators is not taken into account. In accordance with the recursion of indexes and the interdependence between indicators, the focus of this paper will give an appropriate evaluation of $\mathrm{HCW}$ treatment technologies and choose the best disposal technology, so as to further maintain the health of the populations.

\section{Problem presentation}

Unreasonable waste disposal, directly free to throw away, causes very serious losses. It will pollute the soil, water, then the disease will come. Therefore, the proper and reasonable disposal of medical waste is of great importance.

\subsection{Consideration of multi-objective decision-making(MODM) in the evaluation of HCW treatment methods}

In this paper, there are many ways to dispose of medical wastes. However, each hospital system may need to dispose of wastes without any pollution and bad impact on the environment and society. Besides that, the hospital also should satisfy high-tech, low-cost goals. This is a MODM problem, meeting a number of goals, and this is a very complicated process.

\subsection{Consideration of the interdependence between indicators of the $\mathrm{HCW}$ treatment methods}

To data, many scholars have made relevant researches on the rational use of medical waste disposal methods. However, in my field of vision, scholars at home and abroad are still not very mature in the research on this aspect. The foreign research system for the evaluation of HCW disposal methods has basically taken shape. However, it's a few researches that consider the recursion of indicators and interdependence of evaluation indexes. Based on the recursion of indicators and the interdependence between them, a reasonable evaluation of medical waste disposal methods is made and the best disposal technique is selected.

Based on selecting lots of indicators, taking the interdependence between indicators into account and satisfying the various constraints, this paper chooses the optimal HCW 
treatment technology, thereby establishes a more systematic and comprehensive medical management system to adapt to the changes in social environment.

\section{Methodology}

According to the basic principles of "systematic principles of HCW disposal, typical principles of indicators, concise scientific principles, comparable and operated principles and comprehensive principles" that are related to the evaluation index system of HCW treatment technologies, and the main influence factors about building the evaluation of $\mathrm{HCW}$ treatment technologies, there are some primary indexes as follows: Technical performance, Environment, Economic, Social, etc.( Ata R et al. 2016, Xiao W et al. 2005 ). Based on a certain criterion, experts in relevant fields decide the impact of the same level of indicators, and mark 1-9 degree of influence and determine the weight. Using ANP method ranks HCW treatment technologies, and the best results can be gained. This paper's index system is shown in Fig 1.

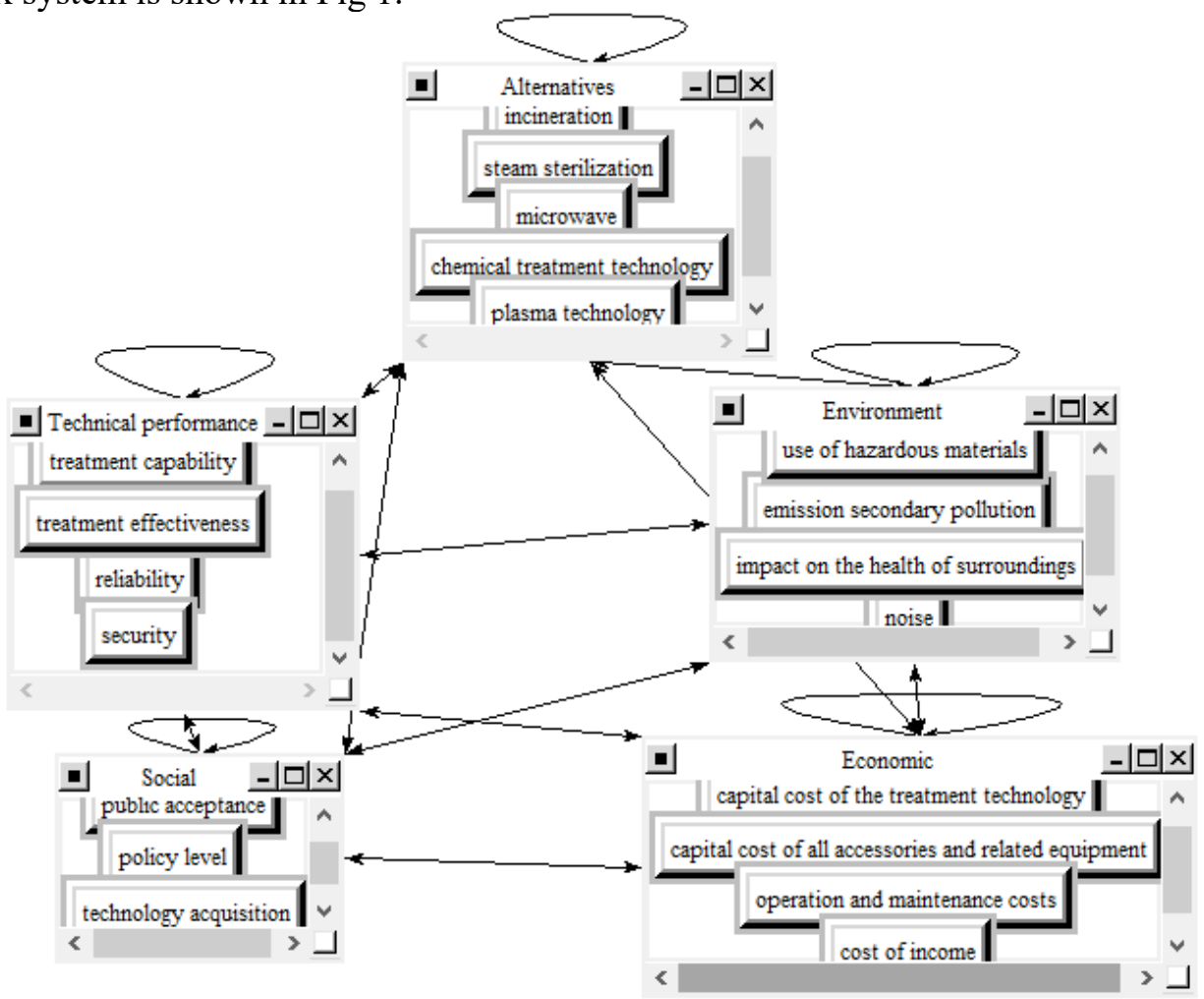

Figure 1. HCW treatment technologies evaluation index diagram

\section{Illustrative example}

Hospital A, a Grade-A hospital located in X City, S Province, has more than 1,000 beds, with 256-layer high-end spiral CT, various scanning systems and analysis systems. There are many departments, such as Respiratory Medicine, Cardiology, Urology, Gynecology and so on, a total of 21 administrative functions departments and 51 clinical and medical departments. Like this hospital there are about 25-30 barrels a day of medical waste at a rate of about $25 \mathrm{~kg}$ a barrel for a total of $375 \mathrm{~kg}$ to $450 \mathrm{~kg}$. Hospital A has been primarily disposing of $\mathrm{HCW}$ internally using incineration, steam sterilization, microwave, chemical treatment technology and plasma technology. The indicators in the model are decided by 
experts. In this paper, there are 5 experts from medical waste managers, government agents and environmental protection specialists and other field personnel. According to the information collected from the disposal technologies of the hospitals, the expert group determines the interaction of each indicator. Based on the comparison of evaluation criterion between two HCW disposal methods under one criteria, we can draw multiple judgment matrices, such as matrix (1). Using the super decision software to solve the model, the weight of the unweighted matrix is obtained. After that we can normalize the unweighted matrix to obtain the weighted hyper matrix and the limit super matrix. Finally, get the result of software calculation in Fig 2 and steam sterilization is the most suitable $\mathrm{HCW}$ treatment technology after comparison.

$$
W_{s}=\left[\begin{array}{cccc}
1 & 1 / 5 & 3 & 4 \\
5 & 1 & 7 & 6 \\
1 / 3 & 1 / 7 & 1 & 2 \\
1 / 4 & 1 / 6 & 1 / 2 & 1
\end{array}\right]
$$

\begin{tabular}{|c|c|c|c|c|}
\hline \multicolumn{5}{|c|}{$\begin{array}{l}\text { Here are the overall synthesized priorities for the } \\
\text { alternatives. You synthesized from the network Supe } \\
\text { Decisions Main Window: super decision.sdmod }\end{array}$} \\
\hline Name & Graphic & Ideals & Normals & Raw \\
\hline $\begin{array}{l}\text { chemical treatment } \\
\text { technology }\end{array}$ & & 0.346329 & 0.119703 & 0.021451 \\
\hline incineration & & 0.490691 & 0.169600 & 0.030392 \\
\hline microwave & & 0.691129 & 0.238879 & 0.042807 \\
\hline plasma technology & & 0.365072 & 0.126182 & 0.022612 \\
\hline steam sterilization & & 1.000000 & 0.345635 & 0.061938 \\
\hline
\end{tabular}

Figure 2. HCW treatment technologies evaluation index comprehensive weight

\section{Conclusions}

On the basis of previous studies on the evaluation of HCW treatment technologies, this paper uses the expert scoring to determine the weights in terms of the interdependence between the indicators. Afterwards, the evaluation system of HCW treatment technologies and ANP model are built. Finally, the model is solved by super decision software. The result reflects the feasibility and operability of the system and model, and it's better to make up the deficiency that ignoring the interdependence between the indicators in existing papers. The aim is to reduce the impact of $\mathrm{HCW}$ on environment and society and improve the medical and health management system simultaneously. In future research, the proposed model can be modified by objective or the combination of subjective and objective to determine the weights before it is applied to solve the related problems.

\section{References}

Abd ElSalam, M. M. (2010). Hospital waste management in EL-Beheira Governorate, Egypt. Journal of Environmental Management, 91(3), 618-629.

Ata R., Kamyar, Y., Mohammad, H., Saeid, P., Amirhosein, M., Masud, Y., \& Ramin, N. 
ISAHP Article: A Style Guide for Paper Proposals To Be Submitted to the International Symposium on the Analytic Hierarchy Process 2018, Hong Kong, HK.

(2016). Assessment and selection of the best treatment alternative for infectious waste by modified sustainability assessment of technologies methodology. Journal of Environmental Health Science \& Engineering, 14(1), 1-14.

Chao, L., You, J. X., Liu, H. C., \& Ping, L. (2016). Health-care waste treatment technology selection using the interval 2-tuple induced TOPSIS method. International Journal of Environmental Research \& Public Health, 13(6), 562.

Ferreira, V., \& Teixeira, M. R. (2010). Healthcare waste management practices and risk perceptions: findings from hospitals in the Algarve region, Portugal. Waste Management, 30(12), 2657-2663.

Liu, H. C., Wu, J., \& Li, P. (2013). Assessment of health-care waste disposal methods using a vikor-based fuzzy multicriteria decision-making method. Waste Management, 33(12), 2744-51.

Liu, H. C., You, J. X., Lu, C., \& Chen, Y. Z. (2015). Evaluating health-care waste treatment technologies using a hybrid multicriteria decision making model. Renewable \& Sustainable Energy Reviews, 41, 932-942.

Manga, V. E., Forton, O. T., Mofor, L. A., \& Woodard, R. (2011). Health care waste management in Cameroon: a case study from the Southwestern Region. Resources Conservation \& Recycling, 57(6), 108-116.

Patwary, M. A., O’Hare, W. T., \& Sarker, M. H. (2011). Assessment of occupational and environmental safety associated with medical waste disposal in developing countries: a qualitative approach. Safety Science, 49(8), 1200-1207.

Xiao, W., Nie, X., Feng, B. (2005). Comprehensive evaluation system for comprehensive evaluation system of clinical waste disposal engineering and its auxiliary software design. Environmental science research, 18(s1):57-62. 